\title{
Obstructive sleep apnea in children: a critical update
}

This article was published in the following Dove Press journal:

Nature and Science of Sleep

24 September 2013

Number of times this article has been viewed

\author{
Hui-Leng Tan ${ }^{1,2}$ \\ David Gozal' \\ Leila Kheirandish-Gozal' \\ 'Sections of Pediatric Sleep \\ Medicine and Pediatric Pulmonology, \\ Department of Pediatrics, Comer \\ Children's Hospital, Pritzker School \\ of Medicine, The University \\ of Chicago, Chicago, IL, USA; \\ ${ }^{2}$ Department of Paediatric \\ Respiratory Medicine, Royal \\ Brompton Hospital, London, UK
}

\begin{abstract}
Obstructive sleep apnea (OSA) in children is a highly prevalent disorder caused by a conglomeration of complex pathophysiological processes, leading to recurrent upper airway dysfunction during sleep. The clinical relevance of OSA resides in its association with significant morbidities that affect the cardiovascular, neurocognitive, and metabolic systems. The American Academy of Pediatrics recently reiterated its recommendations that children with symptoms and signs suggestive of OSA should be investigated with polysomnography (PSG), and treated accordingly. However, treatment decisions should not only be guided by PSG results, but should also integrate the magnitude of symptoms and the presence or absence of risk factors and signs of OSA morbidity. The first-line therapy in children with adenotonsillar hypertrophy is adenotonsillectomy, although there is increasing evidence that medical therapy, in the form of intranasal steroids or montelukast, may be considered in mild OSA. In this review, we delineate the major concepts regarding the pathophysiology of OSA, its morbidity, diagnosis, and treatment.
\end{abstract}

Keywords: adenotonsillar hypertrophy, polysomnography, pathophysiology, morbidity, treatment, pediatric sleep disordered breathing

\section{Introduction}

Children with obstructive sleep apnea (OSA) experience partial or complete obstruction of the upper airway during sleep, with resultant oxygen desaturation and hypercapnia, leading to increasing respiratory effort and attendant changes in intrathoracic pressures, ultimately culminating in subcortical or cortical arousals. Following such arousals, the child will typically drift back to sleep, and the cycle then repeats itself, with similar episodes occurring throughout the night and resulting in sleep fragmentation and nonrestorative sleep. ${ }^{1}$ It is now recognized that pediatric OSA is not only a common health problem, but also one that can result in significant morbidity. Estimates of prevalence vary, depending on the populations studied and on the stringency of the diagnostic criteria but are traditionally reported to range between $1 \%-5 \%$, with the peak prevalence occurring at 2-8 years of age. ${ }^{1-5}$

The distinctive symptoms of OSA in children are remarkably scarce and usually require a high level of suspicion or alternatively, require systematic implementation of explorative screening questions to enable their detection. Common nighttime symptoms include snoring, excessive sweating, restless sleep, mouth breathing, apneas, gasping, labored or paradoxical breathing, and hyperextension of the neck during sleep. Daytime symptoms most commonly include difficulty concentrating, behavioral and mood problems, morning headaches, excessive daytime sleepiness (EDS), and failure to thrive. ${ }^{1}$
Correspondence: Leila Kheirandish-Goza Pediatric Sleep Medicine, Department of Pediatrics, Pritzker School of Medicine, The University of Chicago, 584I S Maryland Avenue/MC2II7, Chicago, IL 60637-I470, USA

Tel +l 7738343815

Fax + I 773834 I444

Email Igozal@peds.bsd.uchicago.edu submit your manuscript $\mid$ www. dovepress.com

Dovepress

http://dx.doi.org//0.2147/NSS.S51907 
In this review, we will selectively identify issues of contention in pediatric OSA that address aspects of the pathophysiology, morbidity, diagnosis, and treatment of the disease. As such, this work is not meant to serve as a comprehensive and exhaustive overview, but rather, to illustrate and invigorate the debate on issues for which either conclusive evidence is lacking or a substantial level of conflictive evidence is present.

\section{Pathophysiology of OSA}

Although interactively related, the pathophysiological factors involved in OSA can be broadly and arbitrarily divided into anatomical factors that effectively reduce airway caliber and those that promote increased upper airway collapsibility (Figure 1). Examples of the former include craniofacial factors, eg, a small or retropositioned mandible, a large or retropositioned tongue, increased pharyngeal fat pads, and hypertrophic upper airway lymphoid tissues (particularly of the adenoids and tonsils). Among the factors underlying collapsibility, the presence of upper airway inflammation and altered neurological reflexes involving respiratory control of upper airway muscles emerge as the most prominent. These elements readily explain why children at higher risk of OSA include those with craniofacial syndromes (eg, Treacher Collins syndrome, Crouzon syndrome, Apert syndrome, and Pierre Robin sequence), achondroplasia, cerebral palsy, neuromuscular disorders, myelomeningocele, sickle cell disease, trisomy 21, allergic rhinitis, asthma, micrognathia, mucopolysaccharidoses, macroglossia, Afro Caribbean race, and those who are obese. ${ }^{6}$ Notwithstanding, the fundamental understanding of the individual mechanistic factors explaining why children with similar degrees of adenotonsillar hypertrophy may either suffer from OSA or not even snore during sleep remains somewhat elusive.

To resolve some of these issues, Arens et al used magnetic resonance imaging (MRI) techniques to delineate in detail the upper airway and surrounding tissues as well as the lower facial skeletal structure, in children with OSA. ${ }^{7}$ The volumetric measurements obtained indicated that the adenoids and tonsils were significantly increased in children with OSA compared with matched controls, concomitant with smaller upper airway volumes. Furthermore, in this case-control study, when the percent difference of the combined tonsil and adenoidal volume between each subject and his/her corresponding age-, height-, weight-, gender-, and ethnicity-matched control was plotted against the apnea hypopnea index, a positive correlation was seen. The volume of the soft palate was also noted to be on average 30\% larger in subjects with OSA, adding additional restriction to the airway lumen size. However, no study has addressed the major question as to what factors differ between children with OSA and no OSA, when matched for the degree of adenotonsillar tissues, or alternatively, why in otherwise similar children with OSA, adenotonsillectomy (AT) may yield different surgical outcomes as far as the degree of resolution of OSA. Furthermore, the interactions between obesity and adenotonsillar hypertrophy are only now being elucidated. ${ }^{8-10}$

In addition to enlarged adenoids and tonsils, children with OSA have recently been shown to also have hypertrophy/ hyperplasia of the lymphoid tissues in other regions of the airway as well, such as in the deep cervical lymph nodes (ie, those outside Waldeyer's ring). ${ }^{11}$ Upper respiratory tract perturbations, such as prominence of the inferior nasal turbinates, deviation of the nasal septum, middle ear effusions, and opacification of the sinuses have also been described. ${ }^{12}$ These observations raise the question as to whether there is in fact, a broader disorder affecting the airway as a whole, mediated by inflammatory processes, chronic or recurrent infectious processes, or a combination thereof. ${ }^{13}$ In other words, are there unique mechanisms that underlie the lymphoid tissue proliferation that leads to OSA as compared with mechanisms that lead to such proliferation but that do not elicit OSA?

The exact mechanisms underlying follicular lymphoid proliferation and hyperplasia of the tonsils and adenoids remain poorly understood. When tonsillar tissues from children with OSA were placed in an in vitro culture system, the proliferative rates of the associated cluster of differentiation (CD)3, CD4, and CD8 cells were higher compared with tonsillar tissues from children with recurrent tonsillitis. ${ }^{14,15}$ Furthermore, the proinflammatory cytokines tumor necrosis factor (TNF)- $\alpha$, interleukin (IL)-6, and IL-1 $\alpha$ were more highly expressed in the OSA-derived tonsils. It is postulated that respiratory viruses and possibly recurrent vibration of the upper airway wall may promote localized inflammation. Exhaled breath condensate levels of leukotriene B4 and cysteinyl leukotrienes have been reported to be higher in children with OSA. ${ }^{16}$ Similarly, induced sputum from children with OSA has been shown to exhibit increased neutrophilia compared with controls. ${ }^{17}$

As indicated above, anatomical factors are clearly not the whole story for OSA in children: we have all seen children with large kissing tonsils who do not have OSA. Furthermore, the apnea-hypopnea index (AHI) has not been shown to directly correlate with airway volume, ${ }^{7}$ and the coefficients 
of correlation between AHI and adenotonsillar size have been found to be usually relatively weak, albeit statistically significant, ${ }^{9,18}$ suggesting that other factors feature in the pathophysiology of pediatric OSA. The concept of airway collapsibility has thus been proposed to provide a more comprehensive and unified approach to this issue.

One of the earliest studies of airway collapsibility in children with OSA was by Marcus et al. ${ }^{19}$ In the Starling resistor mode ${ }^{20}$ of the upper airway, under conditions of flow limitation, the maximum inspiratory airflow is determined by the pressure changes upstream (nasal) to a collapsible locus of the upper airway and is independent of the downstream (tracheal) pressure generated by the diaphragm. The pressure at which the upper airway collapses has been termed the critical closing pressure (Pcrit). Pcrit is thus, an objective measure of airway collapsibility and was found to be higher (ie, less negative) in children with OSA than in those with primary snoring and correlated with the AHI. In other words, children with OSA had demonstrably more collapsible upper airways during sleep. However, during wakefulness, active neural processes preserve upper airway patency and make it difficult to recognize such increased collapsibility. Interestingly, the surgical treatment of OSA was associated with a decline in Pcrit, ie, the upper airways became less collapsible post-AT. ${ }^{19}$

Gozal and Burnside therefore postulated that measurement of upper airway dynamics using acoustic pharyngometry in the awake child, before and after application of local anesthetic to the pharyngeal introitus, may provide a useful clinical adjunct to the diagnosis of OSA. ${ }^{21}$ Upper airway collapsibility was determined from the percentage change in cross-sectional area before and after topical anesthesia, and an upper airway collapsibility less than or equal to $-30 \%$ proved to be highly sensitive and specific in the identification of children with an AHI $>5 /$ hour of total sleep time (TST). In agreement with these findings, another group also showed that children with OSA have a more collapsible upper airway than do normal children, even when awake, using the negative expiratory pressure (NEP) technique. ${ }^{22}$ However, although this technique could distinguish between children with OSA and normal controls, it could not distinguish between children with OSA and primary snorers. Similar approaches using the Müller maneuver have also been proposed as potentially predictive of OSA severity. ${ }^{23}$

Thus, it is probably safe to conclude that a multiplicity of causative factors appear to coexist in every child with OSA. As a corollary to such assumptions, children with sickle cell disease have, for example, not only reduced upper airway size due to overgrowth of the surrounding lymphoid tissues, ${ }^{24}$ but they are also likely to be of African American ethnicity, which is also a risk factor for OSA. However, not all children with sickle cell disease have OSA, and those who do may have less prominent upper airway reflexes than those who do not. ${ }^{25}$

\section{Obesity}

With the obesity epidemic that is sweeping through many of the developed countries, the demographics of childhood OSA appear to be changing. Compared with the classical presentation of a child with adenotonsillar hypertrophy and failure to thrive, as described in the not so distant past, nowadays, there are increasing numbers of children being diagnosed with OSA who are obese. Although all of the pathophysiological mechanisms described above for nonobese children would still remain applicable in the context of obesity, it is likely that other contributors may be operational in obese children as well. Indeed, not all obese children with OSA have adenotonsillar hypertrophy, often present at a slightly later age, and their clinical presentation is more likely to resemble the adult OSA phenotype. ${ }^{26}$

Obesity has become one of the most significant risk factors for OSA in children. ${ }^{27}$ Each $1 \mathrm{~kg} / \mathrm{m}^{2}$ increment in body mass index above the 50th percentile (adjusted for gender and age) is associated with an increased risk of OSA by $12 \%$. However, we should also point out that $45 \%$ of obese children with OSA also have evidence of adenotonsillar hypertrophy. When the upper airways of obese children with OSA were critically examined using MRI volumetric approaches, an increased size of upper airway lymphoid tissues, parapharyngeal fat pads, and abdominal visceral fat became apparent. ${ }^{10}$ When obese and nonobese children with OSA were matched for age, gender, ethnicity, and obstructive AHI, the size of the adenotonsillar tissues in obese children was smaller, while their Mallampati scores were higher, indicating that the presence of obesity increases the risk for OSA, not only via increased lymphadenoid tissue proliferation, but also, by restricting the overall pharyngeal space. ${ }^{9}$

Furthermore, the percentage of obese children who have residual OSA post-AT is significantly higher than in nonobese children. ${ }^{28}$ It has thus been suggested that alterations in the functional mechanisms regulating upper airway patency may be present in obese children and promote increased airway collapsibility. The presence of a linear association between obesity and $\mathrm{P}_{\text {crit }}$ values would then explain, at least in part, the increased propensity of these subjects to develop OSA. Fatty infiltrates within the compartments of the upper airway 
structures and the neck are likely to result in upper airway narrowing and increased pharyngeal collapsibility. Central obesity also reduces the functional residual capacity of the lungs, due to abdominal visceral fat impinging on the chest cavity, limiting diaphragmatic descent, particularly when lying in the supine position; ${ }^{29}$ in addition, thoracic fat weighing on the chest wall can effectively decrease lung compliance, leading to hypoventilation, atelectasis, and ventilation-perfusion mismatch. The reduced lung volumes may decrease airway stiffness by reducing the tracheal tethering effect, further increasing the risk of upper airway collapse during sleep. In a recent study, in which MRI scans were performed both pre- and post-AT in obese children with OSA, there was not only increased residual adenoidal tissue, but also the volume of the tongue and soft palate were greater after AT. ${ }^{8}$ Taken together, all of these factors could be operational contributors to the low success rate of AT reported in obese children with OSA. ${ }^{28,30-32}$

A reciprocal interaction between obesity and OSA has also been suggested, whereby in addition to the contributions of obesity to OSA discussed above, OSA may also be contributing to the pathogenesis of obesity. Leptin is a key hormonal regulator of appetite and metabolism, mainly secreted by adipocytes, that promotes satiety and reduces food intake. In contrast, ghrelin is an orexigenic hormone secreted in the gut. OSA can induce leptin resistance and increase ghrelin levels, both of which can potentiate obesogenic behaviors, in particular, the intake of high-calorie comfort foods. ${ }^{33}$ OSA can also cause EDS and fatigue, both of which are likely to reduce the commitment to and engagement in physical activity. ${ }^{33}$ The low-grade inflammatory responses induced by OSA could further interact and potentiate the underlying inflammatory responses, due to obesity, and exacerbate the morbid phenotypes associated with either obesity or OSA. ${ }^{34}$

\section{OSA and inflammation}

It is now recognized that OSA can promote the activation and propagation of systemic inflammatory responses. ${ }^{35}$ Elevation of proinflammatory cytokines such as IL-6, interferon (IFN)- $\gamma$ and TNF- $\alpha$ have all been reported, ${ }^{36-38}$ albeit inconsistently, in children with OSA, while levels of the anti-inflammatory cytokine IL-10 were reduced. ${ }^{39}$ Microarray analyses of ribonucleic acid (RNA) from peripheral leukocytes has revealed the coordinated recruitment of functionally relevant gene clusters involved in the regulation and propagation of inflammatory pathways and the inflammasome. ${ }^{40}$ One of the potential mechanisms responsible for the initiation of inflammation may reside in molecular events in specific genes. For example, the promoter region of the FOXP3 gene, which controls the transcriptional fate and differentiation of lymphocytes into regulatory $\mathrm{T}$ lymphocytes (Tregs), exhibits severity-dependent increases in methylation in pediatric OSA. ${ }^{41}$ Such epigenetic alterations were subsequently linked to the presence of reduced counts of Tregs in the peripheral blood of children with OSA, ${ }^{42}$ a significant finding considering the major role that Tregs play in the suppression of inflammation. It is therefore possible that differentially orchestrated responses of various tissues to the presence of OSA-induced perturbations may further interact with environmental factors and intrinsic genetic variance to elicit a wide spectrum of inflammatory phenotypes that is linked to end-organ morbidities. ${ }^{43}$

\section{Morbidity of OSA}

The foremost relevance of OSA relates to the fact that it imposes a vast array of morbidities. It has been proposed that such morbidities result from the combination of the activation of inflammatory cascades alluded to above and the induction of oxidative stress mechanisms, collectively leading to cellular injury and dysfunction, senescence, and various forms of cell death. Although these mechanisms are probably universal across the various targeted organs, we will describe each of the morbid consequences in greater detail below. They are also summarized in Figure 2.

\section{Cardiovascular system}

Arguably, one of the most serious complications of severe OSA is pulmonary hypertension, and the resultant cor pulmonale and right-sided heart failure if left untreated. ${ }^{44-46}$ Fortunately, with increased awareness and earlier diagnosis, the frequency of such cases is now much less commonly seen. However, it is unclear whether pulmonary hypertension will develop only in the severest cases, such that increased recognition and awareness of sleep disordered breathing in children would lead to a reduced likelihood of long-standing disease and concurrent pulmonary hypertension, or whether the current techniques for noninvasive assessment of the pulmonary circulation in children are insufficiently sensitive to detect much milder involvement of the pulmonary vasculature. Furthermore, it is also unclear whether chronic mild intermittent hypoxia may result in lesser recruitment of the pulmonary vascular network than following exposures to sustained hypoxia of similar duration. ${ }^{47,48}$ This issue merits further research, particularly considering that the occurrence of intermittent hypoxia and mobilization of the lung capillary 


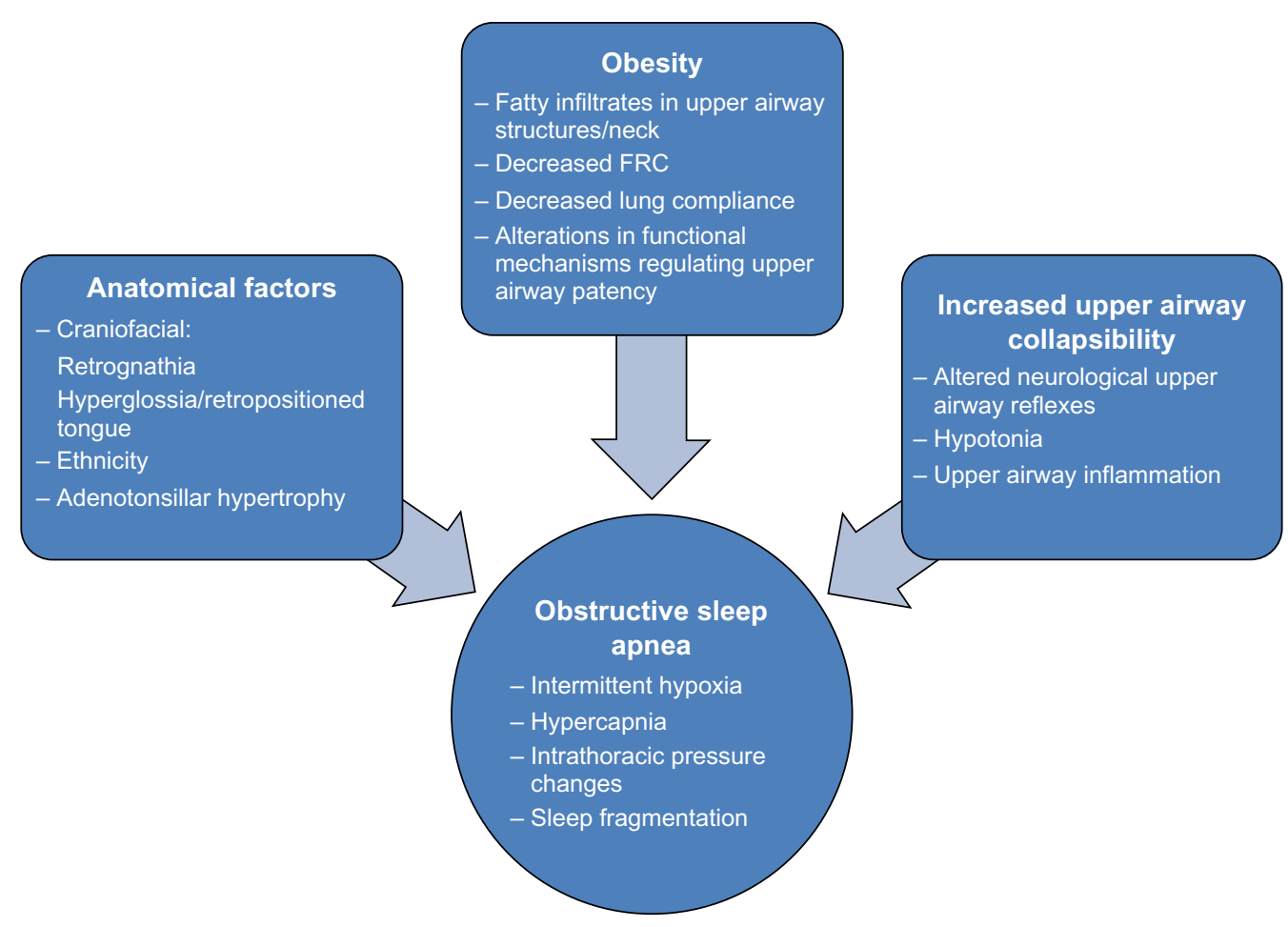

Figure I Pathophysiological factors involved in pediatric OSA.

Abbreviations: FRC, functional residual capacity; OSA, obstructive sleep apnea.

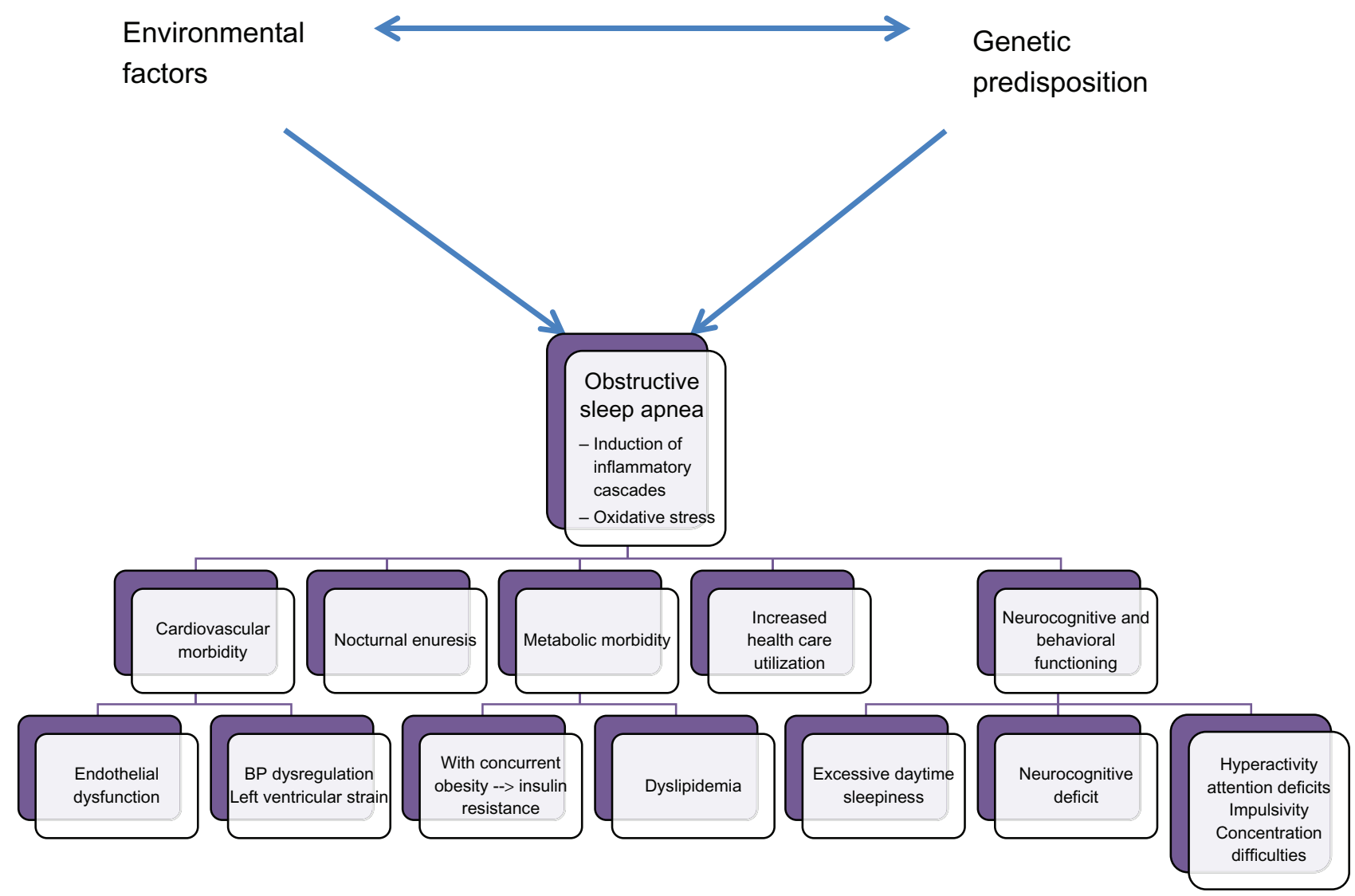

Figure 2 Morbidity of pediatric OSA.

Abbreviations: BP, blood pressure; OSA, obstructive sleep apnea. 
endothelial network may promote long-term susceptibility to pulmonary hypertension even during adulthood. ${ }^{49}$ Notwithstanding, there is increasing evidence that OSA can impose even "subclinical" effects on the autonomic and cardiovascular systems and promote cardiovascular disturbances in blood pressure (BP) regulation, ventricular remodeling, and endothelial dysfunction, all of which can lead to farreaching detrimental consequences if left unattended. ${ }^{51-66}$

One of the earliest studies exploring the relationship between BP and OSA in children found that children with OSA tend to have higher diastolic BP during sleep compared with children with primary snoring. ${ }^{50}$ The degree of increase in BP during rapid eye movement (REM) sleep has also been shown to correlate with the severity of OSA, ${ }^{51}$ which is perhaps unsurprising considering that OSA, in the majority of children, tends to occur during REM sleep and that surges in arterial BP have been shown to occur after respiratory event termination. ${ }^{52}$ Amin et al studied slightly older children, and found that children with OSA had evidence of BP deregulation: they had significantly greater mean BP variability during wakefulness and sleep, a higher night-to-day systolic BP, and marked reductions in nocturnal dipping of the mean BP. ${ }^{53}$ In fact, children with OSA had night-to-day systolic BP ratios that surpassed the established cutoff ratios of 0.899 for females and 0.9009 for males, both of which are known to increase the risk for cardiovascular morbidity in adults. ${ }^{54} \mathrm{~A}$ few years later, the same group of investigators reported that children with OSA exhibit increases in morning BP surges, BP load, and 24-hour ambulatory BPs compared with healthy controls. ${ }^{55}$ Furthermore, these differences were associated with left ventricular remodeling, and the effects were apparent even in children with mild OSA. Interestingly, even habitually snoring children without evidence of OSA, ie, "primary snorers," were also found to be at higher risk for elevations in systemic BP. ${ }^{56-58}$

The evidence of left ventricular strain and reduced contractility reported by Amin et al ${ }^{55}$ led to exploration of potential mechanisms that may account for the left ventricular involvement in OSA. Among the various putative factors, assessment of changes in brain natriuretic peptide (BNP) seemed logical, considering that this 32 amino acid peptide is released by cardiac myocytes in response to cardiac wall distension. Indeed, overnight changes in BNP levels were found to be greater in children with moderate/severe OSA compared with mild OSA and controls,${ }^{59}$ most likely related to the increased and more frequent negative intrathoracic pressure swings seen in more severe OSA, further supporting the presence of nocturnal cardiac strain in children who have moderate to severe OSA. It remains unknown whether the left ventricular changes associated with pediatric OSA are completely reversible or indicate a group of susceptible individuals at risk for more adverse cardiovascular disease during adulthood.

Endothelial dysfunction is thought to be an early precursor to atherosclerosis. Assessment of postocclusive hyperemic responses in children, using various methodologies, such as flow-mediated dilation, pulse arterial tonometry, and laser Doppler reperfusion kinetics, ${ }^{60-63}$ has revealed significant impairment in endothelial function among children with OSA compared with controls. Furthermore, although the majority of these children demonstrated resolution of the endothelial dysfunction following treatment with $\mathrm{AT},{ }^{60}$ a subgroup who also had a strong family history of cardiovascular disease did not show the anticipated improvements in endothelial function, suggesting that the effects of OSA in a genetically susceptible subset of children may persist for unknown periods of time, potentially into adulthood. As anticipated, in children with concurrent obesity and OSA, the magnitude of endothelial dysfunction was greater than when either condition was present in isolation, suggesting the convergence of the deleterious consequences of obesity and OSA..$^{26,34,64-65}$ The evidence for severity-dependent alterations in endothelial function was confirmed in children with OSA, using pulse arterial tonometry to derive the reactive hyperemia index, whereby significant differences in evening-to-morning changes of endothelial function emerged in children with OSA, and such overnight changes in endothelial function were closely associated with the severity of the disease..$^{62}$ It should be stressed, however, that not every child with OSA manifests endothelial dysfunction. ${ }^{64}$ One potential explanation for the variance in endothelial phenotype of pediatric OSA may well reside in the intrinsic ability to recruit endothelial progenitors to the circulation via the release of stromal derived factor 1 (SDF-1). ${ }^{61}$

C-reactive protein (CRP), an acute-phase reaction protein produced in the liver, has emerged as a robust and independent predictor of cardiovascular morbidity and is extensively used to stratify the risk for ischemic heart disease. ${ }^{66}$ It has been postulated that CRP may even participate directly in atheromatous lesion formation, through reduction of nitric oxide synthesis and induction of the expression of adhesion molecules in endothelial cells. ${ }^{67,68}$ Increased CRP levels have been demonstrated in children with OSA, correlate with severity of the disease, and decrease following effective treatment. ${ }^{69-72}$ It should be stressed that not all children with OSA have elevated CRP levels, as the interplay of genetic 
variants in IL-6 and CRP genes as well as environmental factors plays an important role (Gozal et $\mathrm{al}^{72}$ ). However, we would surmise that the children in whom CRP levels are elevated constitute a higher-risk group for the development of long-term cardiovascular complications. Indeed, markers of vascular injury and endothelial activation, such as adhesion molecules, myeloid-related protein 8/14, fatty acid-binding protein, and circulating microparticles have all been shown to be elevated in children with OSA and are associated with the presence of endothelial dysfunction. ${ }^{73-76}$ Efforts are now ongoing to develop a panel of biomarkers that may identify those children at risk for cardiovascular morbidity as a result of OSA.

\section{Metabolic system}

Although in adult cohorts OSA has been identified as an important risk factor for insulin resistance and diabetes, ${ }^{77-83}$ the presence of this association in children is not as clear cut and may well depend on factors such age, ethnicity, pubertal status, the degree of inflammatory response, and the concurrent presence of obesity.

In a community-based study of predominantly postpubertal adolescents, strong associations were demonstrated between OSA and the metabolic syndrome, as well as with individual metabolic parameters, such as fasting insulin and homeostatic model assessment (HOMA). ${ }^{29,84,85}$ Sleep fragmentation and intermittent hypoxia were also found to be associated with decreased insulin sensitivity in obese adolescent boys. ${ }^{86}$ In younger children, OSA was associated with reduced insulin sensitivity only when obesity was concurrently present, ${ }^{87,88}$ and effective treatment of OSA ameliorated HOMA in these children. ${ }^{89}$ However, when highly sensitive bioinformatics approaches and pathway analyses were employed, in conjunction with transcriptome microarray analyses, in children with primary snoring, alterations in insulin homeostatic mechanisms emerged and were further confirmed with HOMA in such children, suggesting that even mild perturbations in sleep may impose subclinical changes in peripheral tissue insulin receptor sensitivity. ${ }^{90}$

OSA has also been implicated in rises in low-density lipoprotein (LDL) cholesterol with concomitant decreases in high-density lipoprotein (HDL) cholesterol, in both obese and nonobese children. ${ }^{89,91}$ Significant improvements in lipid profile were observed in all children after treatment of their OSA.

Even in childhood, evidence of end-organ morbidity, in the form of fatty liver disease, has been demonstrated in obese children with OSA..$^{92-94}$ Of note, the treatment of
OSA, usually with AT followed by continuous positive airway pressure (CPAP), in a large subset of these obese children resulted in improved liver serum aminotransferases in the majority of the patients. ${ }^{92}$

\section{Neurocognitive and behavioral functioning}

The first seminal paper to highlight the potential causative links between OSA and its detrimental consequences on academic performance was published by Gozal in $1998 .{ }^{95}$ In a prospective study looking at 297 first-grade children whose school performance was in the lowest tenth percentile of their class, screening for OSA revealed a marked elevation in the prevalence of OSA. Furthermore, the children who were treated for OSA showed significant academic improvements in their school grades the subsequent year, while children who had OSA but who were not treated failed to improve academically. Since then, there have been numerous studies reporting the association between OSA and neurocognitive and behavioral morbidity, and several, albeit not all, studies have shown improvements in some of these functions after treatment. ${ }^{32,96-107}$ Impairments in executive functioning have also been reported: the Tucson Children's Assessment of Sleep Apnea (TuCASA) study identified a negative correlation between AHI and immediate recall, Full Scale IQ, Performance IQ, and math achievement, while nocturnal hypoxemia adversely affected nonverbal skills. ${ }^{108}$ Children with OSA have also been shown to take longer and need more learning opportunities to learn a pictorial-based, shortterm and long-term declarative memory test. ${ }^{109}$ From the behavioral standpoint, OSA and habitual snoring have been associated with hyperactivity, attention deficits, concentration difficulties, and impulsivity. Therefore, it should come as no surprise that such children are frequently misdiagnosed as having attention deficit hyperactivity disorder. ${ }^{110-112}$ Recent 5-year follow up results from the TuCASA study revealed that youth with untreated OSA exhibited hyperactivity, had attention problems and aggressive behaviors, lower social competencies, poorer communication, and/or diminished adaptive skills. ${ }^{113}$

Notwithstanding such considerations, it is important to emphasize that not all children with OSA exhibit cognitive or behavioral deficits. It is therefore plausible that susceptibility modifiers, both genetic and environmental, may play a role in phenotypic expression. ${ }^{43}$ Accordingly, several genetic factors have been thus far been identified to account for discrepancies in the cognitive functional performance of children with OSA. For example, differences in systemic inflammatory 
responses, as reported by plasma CRP levels, will differentiate children with OSA of similar severity who exhibit or do not exhibit cognitive deficits. ${ }^{114}$ Similarly, genetic variants in a gene critically involved in the formation of free radicals have been shown to account for discrepancies in cognitive outcomes in pediatric OSA. ${ }^{115}$ Additional factors, such as IGF-1 and apolipoprotein E allelic variants, have also been identified as either protective or detrimental to neurocognitive function. ${ }^{116,117}$

Khadra et al further hypothesized that OSA causes changes in regional cerebral blood flow during sleep, thus favoring the occurrence of neurocognitive impairments. ${ }^{118}$ However, these investigators found that the situation was more complex than expected, with both arousal indices and mean arterial pressure being strongly associated with OSA severity. On the one hand, increasing arousal indices were associated with decreasing regional cerebral oxygenation and on the other hand, increasing mean arterial BP was associated with increasing regional brain oxygenation. In other words, OSA can both augment and decrease regional cerebral blood flow. A model based on the interplay between factors such as age, mean arterial pressure, oxygen saturation, REM sleep, gender, arousal index and NREM sleep has been proposed to predict the effect of sleep disordered breathing on regional cerebral oxygenation. The findings linking vascular function and cognitive outcomes were further confirmed in several additional studies, such that the presence of endothelial dysfunction in OSA may serve as a surrogate reporter of altered cognitive functioning. ${ }^{119,120}$

As mentioned above, improvements in learning and behavior occur following treatment of OSA. ${ }^{107}$ However, some neurocognitive consequences may only be partially reversible if left too late, ${ }^{121}$ highlighting the importance of early diagnosis and prompt effective treatment.

\section{Excessive daytime sleepiness}

In contrast to adults, EDS does not tend to be as prominent a symptom in pediatric OSA. Nonetheless, children with OSA have been shown to have higher Epworth Sleepiness Scale (ESS) scores compared with controls $(8.1 \pm 4.9$ versus $5.3 \pm 3.9)(P<0.001) .{ }^{122}$ Objective measurements of EDS using the Multiple Sleep Latency Test have shown that children with OSA have severity-dependent shortening of their sleep latencies but that EDS is relatively infrequent and tends to manifest among more severe and/ or obese patients. Interestingly, the magnitude of sleep latency reduction has been shown to be associated with measures of systemic inflammation, such as plasma TNF- $\alpha$ level, the latter being modulated by polymorphisms in the TNF- $\alpha$ gene. ${ }^{37,123}$

\section{Healthcare utilization}

Interestingly, children with OSA have been reported to have increased health care utilization compared with their peers, predominantly for respiratory infections. ${ }^{124,125}$ From their first year of life to the time of diagnosis, children with OSA had 40\% more hospital visits, 20\% more repeated visits, and higher prescriptions of medication. ${ }^{124}$ Although one might argue that children who have recurrent upper respiratory tract infections may be at higher risk of OSA or that children who have more contact with healthcare professionals are more likely to be screened for OSA, another prospective study by the same group showed that after treatment of OSA by AT, health care utilization was significantly reduced to the extent that total annual health care costs were reduced by a third. ${ }^{126}$ These findings have since been further confirmed in another population-based cohort. ${ }^{127}$

\section{Nocturnal enuresis}

A higher prevalence of nocturnal enuresis has been reported in children with OSA. ${ }^{128-130}$

It has been postulated that increased enuresis may be due to the dampening effects of OSA on arousal responses, to changes in bladder pressure, or potentially associated with secretion of the hormones involved in fluid regulation. A recent systematic review of the literature identified 14 studies investigating OSA and enuresis, in which a third of the total 3,550 children with OSA had a diagnosis of enuresis. ${ }^{129}$ In the seven studies with follow up data, post-AT improvements in enuresis occurred. However, the data were derived from studies with weak design and skewed cohorts, and randomized controlled trials are still needed to establish a more definitive cause-effect relationship between OSA and enuresis in children.

In children with sickle cell disease, a prospective, multicenter cohort study of 221 children demonstrated that enuresis was significantly associated with an AHI of $>2 / \mathrm{hr}$ TST, after adjusting for age and gender. ${ }^{131}$ The authors recommended that children with sickle cell anemia who present with enuresis should be evaluated by a pulmonologist for sleep disordered breathing.

As mentioned previously in the context of nocturnal cardiac strain, changes in BNP have been demonstrated in children with OSA. As BNP increases sodium and water excretion and also influences hormones in the renin-angiotensin pathway and vasopressin, a population-based cohort study aimed 
to examine the relationship between BNP levels and enuresis in habitually snoring children. The presence of habitual snoring was associated with an increased prevalence of enuresis, and morning BNP levels were found to be elevated in children with OSA. Furthermore, children with nocturnal enuresis have been shown to have higher BNP levels compared with those without, at any degree of sleep disordered breathing severity, providing support to the hypothesis that sleep fragmentation and increased release of BNP secondary to OSA may contribute to the higher prevalence of enuresis in habitually snoring children. ${ }^{132}$

\section{Diagnosis}

One of the major difficulties with the diagnostic process of pediatric OSA is the fact that history and clinical examination perform poorly. In a recent reassessment of this issue by the American Academy of Pediatrics (AAP), a positive predictive value of $65 \%$ for history and $46 \%$ for clinical examination were quoted, ${ }^{4}$ essentially representing a success rate equivalent to that of tossing a coin! Unsurprisingly, the AAP recommendations are that children with symptoms of OSA should be referred for further investigation. ${ }^{4}$

In this context, the current gold standard for the diagnosis of OSA, as recommended by the AAP, is a nocturnal, in-lab polysomnography (PSG) study. A typical montage would include several electroencephalography (EEG) channels, chin and anterior tibial electromyography (EMG), bilateral electrooculography, pulse oximeter and pulse waveform, nasal pressure transducer, oronasal airflow thermistor, end-tidal capnography, chest and abdominal respiratory inductance plethysmography, body position sensor, microphone, and real-time synchronized video monitoring. Rechtschaffen and Kales devised the initial sleep staging system in 1968, ${ }^{133}$ which was in use for almost 40 years. The American Academy of Sleep Medicine (AASM) modified and updated the staging criteria in 2007 and further revised it in 2012, with sleep laboratories now scoring according to these newer AASM guidelines. ${ }^{134}$ This approach provides an objective, quantitative evaluation of disturbances in respiratory parameters and sleep patterns, thus allowing patients to be stratified into disease severities and thereby enabling clinicians to tailor clinical management accordingly. However, stratification into severity categories has thus far been performed empirically, without any critical evidence to support one classification approach versus another. There is as of yet, no international consensus regarding the AHI cutoff values for therapy initiation. The current accepted practice has consisted of the use of an arbitrary cutoff for AHI cor- responding to $>3$ standard deviations beyond the mean of the normative AHI in healthy children. Most clinicians would agree that a child with an $\mathrm{AHI}>5$ /hour TST requires treatment and that a child with an AHI $<1$ /hour TST does not have significant OSA. However, the interpretation of the AHI values in between these two cutoffs are fraught with great discord. Some algorithms have recently been proposed and recognize the importance of treating the patient and not just the values obtained from the sleep study. ${ }^{135,136}$ In addition to polysomnographically derived measures, these algorithms take into account factors such as the severity of symptoms, risk factors, and the presence of any OSA-related morbidity and may therefore provide a more coherent, clinically applicable approach to the diagnosis and prioritization of treatment, when OSA is diagnosed in children.

\section{Treatment}

AT is the primary treatment for pediatric OSA for children with adenotonsillar hypertrophy. ${ }^{137}$ The recently published Childhood Adenotonsillectomy Trial (CHAT), which constitutes the first-ever randomized controlled trial (RCT) for OSA, showed that compared with watchful waiting, the surgical treatment of OSA improved symptoms, behavior, and quality of life, even though improvements in the trial's primary endpoint, ie, neuropsychological measures of attention and executive function, did not occur. ${ }^{32}$ However, it is important to note that this study did not include children aged $<5$ years or children with moderate/severe OSA, as it would have been difficult to ethically justify withholding standard treatment from children with significant oxygen desaturation. Furthermore, similar to the findings reported in previous studies, ${ }^{28}$ (discussed below), the presence of particular risk categories, such as African American ethnicity and obesity, was associated with a reduced probability for normalization of the sleep study result after surgery. ${ }^{137}$

Indeed, a large multicenter, retrospective study showed that although the majority of children had marked AHI improvements following AT, residual OSA was still frequent and clinically significant in a relatively large subset. ${ }^{28}$ Residual OSA was particularly prevalent in obese children, children who had severe OSA before surgery (AHI > 20/hour TST), older children (those aged $>7$ years), and children with asthma. ${ }^{28}$ Similar findings have been reported in other studies involving vastly smaller cohorts. In addition, several other risk factors for residual OSA have been identified and include high Mallampati score, African-American ethnicity, craniofacial anomalies, chromosomal defects, and neuromuscular disease (including trisomy 21, achondroplasia, 
Prader-Willi syndrome, and Pierre Robin syndrome). ${ }^{30,138}$ Clinicians should be aware that (1) specific protocols may be needed to direct clinicians to automatically pursue postsurgical sleep studies in a subset of children at high risk for residual OSA; (2) the recurrence of OSA symptoms post-AT warrants reevaluation, particularly in children with the aforementioned risk factors. The role of other surgical procedures, such as tonsillotomy (in lieu of tonsillectomy) alone or in combination with adenoidectomy has not been established, even though advocates for these approaches claim similar outcomes with reduced postoperative pain. ${ }^{139,140}$

In children who manifest residual OSA after AT or in those who present minimally enlarged upper airway or lymphadenoid tissues or who opt not to undergo surgery, positive airway pressure, in the form of CPAP or BiPAP (bilevel positive airway pressure), has been recommended. ${ }^{137}$ Although positive airway pressure can undoubtedly be a highly effective treatment, ${ }^{141,142}$ adherence can be particularly challenging in children, particularly those with behavioral problems or developmental delays. Behavioral modification techniques can improve adherence, but are time and labor intensive, often require admission to the inpatient service and therefore add substantial costs to their implementation, and are impossible to implement without a priori engagement with the child and family. ${ }^{143}$ Indeed, family and demographic factors have been shown to play a large role in CPAP adherence. ${ }^{144}$

A possible and recently proposed alternative to maskbased positive airway pressure is high flow nasal cannula (HFNC) oxygen therapy. Although there has been only one study so far looking at 12 patients on HFNC, ${ }^{145}$ the reduction in AHI was comparable with that of CPAP, leading the authors to postulate that HFNC may be a viable and possibly more child-friendly alternative.

Since less invasive therapies are more desirable, there has been considerable interest in anti-inflammatory agents, particularly leukotriene-receptor antagonists (such as montelukast) and intranasal steroids. ${ }^{146}$ Tonsils from children with OSA have been shown to express increased levels of leukotriene receptors 1 and 2 compared with tonsils from children with recurrent tonsillitis. ${ }^{147}$ Furthermore, the application of leukotriene antagonists in an in vitro cell culture system of tonsillar tissues from children with OSA elicited dose-dependent reductions in cell proliferation and reductions in the secretion of the cytokines TNF- $\alpha$, IL-6, and IL-12. ${ }^{148}$ In an open-label intervention study where children with mild OSA received 16 weeks of montelukast, significant reductions in adenoidal size and respiratory-related sleep disturbances occurred. ${ }^{149}$ These findings have since been reproduced in a recent double-blind, randomized, placebocontrolled trial. ${ }^{150}$

Similarly, the use of in vitro steroids resulted in decreased proliferative rates of mixed tonsillar tissues, and in increased apoptosis and reduction in the secretion of the proinflammatory cytokines IL-6, IL-8, and TNF- $\alpha .{ }^{151}$ A randomized crossover trial of 6 weeks treatment with intranasal budesonide for mild OSA showed reductions in the severity of OSA as well as in the size of adenoidal tissues. Importantly, discontinuation of therapy for 8 weeks did not promote the occurrence of rebound symptoms. ${ }^{152}$ Intranasal fluticasone has also shown similar results. ${ }^{153}$ Use of both montelukast and nasal budesonide for 12 weeks in children who had residual mild residual OSA after $\mathrm{AT}^{154}$ led to significant improvements in the AHI, nadir oxygen saturation, and in the respiratory arousal index, whereas no significant changes occurred over this time period in the control subjects. Anti-inflammatory therapy appears to be gaining wider acceptance in the treatment of mild OSA, such that studies examining the desirable optimal duration of treatment, longer term outcomes, combinatorial approaches, criteria for patient selection for optimal outcomes, etc, are critically needed.

In selected patient populations, some orthodontic procedures, such as rapid maxillary expansion, have been proposed as efficacious. ${ }^{155-157}$ Procedures such as tongue-base suspension and uvulopalatopharyngoplasty have also been studied in children with cerebral palsy and OSA. ${ }^{158}$ Recently, the use of more comprehensive assessments and interventions, including myofascial reeducation has been advocated in a series of uncontrolled studies. ${ }^{159-162}$

In complex or persistent cases of OSA, sleep endoscopy is a technique that enables the exact level of obstruction in the child to be identified, thus facilitating site-specific surgical therapy. ${ }^{163,164}$ Further work to delineate the children who would benefit most from these procedures is needed, but some recent work in obese children and in children with trisomy 21 showed that lingual tonsils may contribute to residual disease and that lingual tonsillectomy may be effective in those cases. ${ }^{165-171}$

\section{Future developments}

Although sleep studies provide an objective measure of sleep disturbance, it is now evident that measures derived from sleep studies are not predictive of OSA-associated morbidities, and therefore, their cost-efficiency in the management of habitually snoring children is less than perfect, particularly considering the high cost, intensity of labor, and family burden that such studies impose. It is possible that 
home-based studies or more restricted multichannel studies may provide a more economical and accessible option in the future, once the appropriate validation studies are conducted. Alternatively, the identification and implementation of diagnostic biomarker approaches may be possible and merits further exploration. ${ }^{172}$

Another important issue in the context of the evaluation of habitually snoring children is the wide spectrum of phenotypic variance that exists in OSA. As with many other diseases, factors such as individual genetic susceptibility and environmental exposures/lifestyle play major contributing roles to the variance in phenotype. In other words, the optimal threshold for diagnosis and treatment is likely different in different children. Simply stated, not every child fulfilling current polysomnographic criteria for OSA manifests end-organ morbidity, ${ }^{173}$ and conversely, some children with primary snoring display neurocognitive or cardiovascular sequelae and/or signs of systemic inflammation, despite a normal sleep study. ${ }^{90,110}$

In the future, algorithms that incorporate measures derived from the sleep study, from blood or urine tests, and from clinical elements obtained during the history and physical examination may provide improved approaches to determining which children require treatment, which children may benefit most from a specific treatment, or which children are at risk for residual disease and require incremental therapies. There has been exciting research into urinary biomarkers as a potential measure. Preliminary data has shown an association between pediatric OSA and significant nocturnal alterations in urinary neurotransmitters. ${ }^{174}$ It is likely that the episodic hypoxemia and arousals that characterize sleep in OSA patients enhances sympathetic activity, therefore leading to increased levels of urinary epinephrine and norepinephrine. Overnight changes in the levels of three other neurotransmitters, notably increases in gamma-aminobutyric acid (GABA), decreases in taurine, and decreases in $\beta$-phenylethylamine (PEA) have appeared to differentiate children with OSA with neurocognitive deficits from those without. ${ }^{174}$

\section{Conclusion}

In summary, the recent decades since the initial description of pediatric OSA in $1976^{45}$ have witnessed extensive and meaningful progress in research on the pathophysiology, morbidity, and treatment of pediatric OSA. However, there are still many fundamental questions to be answered. If the age of personalized medicine is to become a reality, a greater understanding of the mechanisms underlying the pathogenesis of the disease will be required to help develop novel biomarkers and individualized therapies.

\section{Acknowledgments}

LKG and DG are supported by National Institutes of Health grants HL-65270, HL-086662, and HL-107160. HLT was supported by the Scadding Morriston Davies Fellowship.

\section{Disclosure}

The authors report no conflicts of interest in this work.

\section{References}

1. Kheirandish-Gozal L, Gozal D, editors. Sleep Disordered Breathing in Children. A Comprehensive Clinical Guide to Evaluation and Treatment. New York, NY: Springer Science; 2012.

2. Bixler EO, Vgontzas AN, Lin HM, et al. Sleep disordered breathing in children in a general population sample: prevalence and risk factors. Sleep. 2009;32(6):731-736.

3. Li AM, So HK, Au CT, et al. Epidemiology of obstructive sleep apnoea syndrome in Chinese children: a two-phase community study. Thorax. 2010;65(11):991-997.

4. Marcus CL, Brooks LJ, Draper KA, et al; American Academy of Pediatrics. Diagnosis and management of childhood obstructive sleep apnea syndrome. Pediatrics. 2012;130(3):e714-e755.

5. Rosen CL, Larkin EK, Kirchner HL, et al. Prevalence and risk factors for sleep-disordered breathing in 8- to 11-year-old children: association with race and prematurity. J Pediatr. 2003;142(4):383-389.

6. Tauman R, Gozal D. Obstructive sleep apnea syndrome in children. Expert Rev Respir Med. 2011;5(3):425-440.

7. Arens R, McDonough JM, Costarino AT, et al. Magnetic resonance imaging of the upper airway structure of children with obstructive sleep apnea syndrome. Am J Respir Crit Care Med. 2001;164(4): 698-703.

8. Nandalike K, Shifteh K, Sin S, et al. Adenotonsillectomy in obese children with obstructive sleep apnea syndrome: magnetic resonance imaging findings and considerations. Sleep. 2013;36(6):841-847.

9. Dayyat E, Kheirandish-Gozal L, Sans Capdevila O, Maarafeya MM, Gozal D. Obstructive sleep apnea in children: relative contributions of body mass index and adenotonsillar hypertrophy. Chest. 2009;136(1): 137-144.

10. Arens R, Sin S, Nandalike K, et al. Upper airway structure and body fat composition in obese children with obstructive sleep apnea syndrome. Am J Respir Crit Care Med. 2011;183(6):782-787.

11. Parikh SR, Sadoughi B, Sin S, Willen S, Nandalike K, Arens R. Deep cervical lymph node hypertrophy: A new paradigm in the understanding of pediatric obstructive sleep apnea. Laryngoscope. 2013;123(8): 2043-2049.

12. Arens R, Sin S, Willen S, et al. Rhino-sinus involvement in children with obstructive sleep apnea syndrome. Pediatr Pulmonol. 2010;45(10): 993-998.

13. Gozal D. Pediatric OSA: a case for "United We Stand" in the way of a breath. Pediatr Pulmonol. 2010;45(12):1151-1152.

14. Kim J, Bhattacharjee R, Dayyat E, et al. Increased cellular proliferation and inflammatory cytokines in tonsils derived from children with obstructive sleep apnea. Pediatr Res. 2009;66(4):423-428.

15. Serpero LD, Kheirandish-Gozal L, Dayyat E, Goldman JL, Kim J, Gozal D. A mixed cell culture model for assessment of proliferation in tonsillar tissues from children with obstructive sleep apnea or recurrent tonsillitis. Laryngoscope. 2009;119(5):1005-1010.

16. Goldbart AD, Krishna J, Li RC, Serpero LD, Gozal D. Inflammatory mediators in exhaled breath condensate of children with obstructive sleep apnea syndrome. Chest. 2006;130(1):143-148. 
17. Li AM, Hung E, Tsang T, et al. Induced sputum inflammatory measures correlate with disease severity in children with obstructive sleep apnoea. Thorax. 2007;62(1):75-79.

18. Li AM, Wong E, Kew J, Hui S, Fok TF. Use of tonsil size in the evaluation of obstructive sleep apnoea. Arch Dis Child. 2002;87(2): 156-159.

19. Marcus CL, McColley SA, Carroll JL, Loughlin GM, Smith PL, Schwartz AR. Upper airway collapsibility in children with obstructive sleep apnea syndrome. J Appl Physiol. 1994;77(2):918-924.

20. Schwartz AR, Smith PL. CrossTalk proposal: the human upper airway does behave like a Starling resistor during sleep. J Physiol. 2013;591:2229-2232.

21. Gozal D, Burnside MM. Increased upper airway collapsibility in children with obstructive sleep apnea during wakefulness. Am J Respir Crit Care Med. 2004;169(2):163-167.

22. Carrera HL, McDonough JM, Gallagher PR, et al. Upper airway collapsibility during wakefulness in children with sleep disordered breathing, as determined by the negative expiratory pressure technique. Sleep. 2011;34(6):717-724.

23. Thong JF, Pang KP. Clinical parameters in obstructive sleep apnea: are there any correlations? J Otolaryngol Head Neck Surg. 2008;37(6): 894-900.

24. Strauss T, Sin S, Marcus CL, et al. Upper airway lymphoid tissue size in children with sickle cell disease. Chest. 2012;142(1):94-100.

25. Huang J, Pinto SJ, Allen JL, et al. Upper airway genioglossal activity in children with sickle cell disease. Sleep. 2011;34(6):773-778.

26. Gozal D, Kheirandish-Gozal L. Childhood obesity and sleep: relatives, partners, or both? - a critical perspective on the evidence. Ann NYAcad Sci. 2012;1264(1):135-141.

27. Redline S, Tishler PV, Schluchter M, Aylor J, Clark K, Graham G. Risk factors for sleep-disordered breathing in children. Associations with obesity, race, and respiratory problems. Am J Respir Crit Care Med. 1999;159(5 Pt 1):1527-1532.

28. Bhattacharjee R, Kheirandish-Gozal L, Spruyt K, et al. Adenotonsillectomy outcomes in treatment of obstructive sleep apnea in children: a multicenter retrospective study. Am J Respir Crit Care Med. 2010;182(5):676-683.

29. Canapari CA, Hoppin AG, Kinane TB, Thomas BJ, Torriani M, Katz ES. Relationship between sleep apnea, fat distribution, and insulin resistance in obese children. J Clin Sleep Med. 2011;7(3):268-273.

30. Tauman R, Gulliver TE, Krishna J, et al. Persistence of obstructive sleep apnea syndrome in children after adenotonsillectomy. J Pediatr. 2006;149(6):803-808.

31. Mitchell RB, Boss EF. Pediatric obstructive sleep apnea in obese and normal-weight children: impact of adenotonsillectomy on quality-of-life and behaviour. Dev Neuropsychol. 2009;34(5):650-661.

32. Marcus CL, Moore RH, Rosen CL, et al; Childhood Adenotonsillectomy Trial (CHAT). A randomized trial of adenotonsillectomy for childhood sleep apnea. N Engl J Med. 2013;368(25):2366-2376.

33. Spruyt K, Sans Capdevila O, Serpero LD, Kheirandish-Gozal L, Gozal D. Dietary and physical activity patterns in children with obstructive sleep apnea. J Pediatr. 2010;156(5):724-730, 730. e1.

34. Bhattacharjee R, Kim J, Kheirandish-Gozal L, Gozal D. Obesity and obstructive sleep apnea syndrome in children: a tale of inflammatory cascades. Pediatr Pulmonol. 2011;46(4):313-323.

35. Gozal D. Sleep, sleep disorders and inflammation in children. Sleep Med. 2009;10 Suppl 1:S12-S16.

36. Tauman R, O'Brien LM, Gozal D. Hypoxemia and obesity modulate plasma C-reactive protein and interleukin-6 levels in sleep-disordered breathing. Sleep Breath. 2007;11(2):77-84.

37. Gozal D, Serpero LD, Kheirandish-Gozal L, Capdevila OS, Khalyfa A, Tauman R. Sleep measures and morning plasma TNF-alpha levels in children with sleep-disordered breathing. Sleep. 2010;33(3):319-325.

38. Tam CS, Wong M, McBain R, Bailey S, Waters KA. Inflammatory measures in children with obstructive sleep apnoea. J Paediatr Child Health. 2006;42(5):277-282.
39. Gozal D, Serpero LD, Sans Capdevila O, Kheirandish-Gozal L. Systemic inflammation in non-obese children with obstructive sleep apnea. Sleep Med. 2008;9(3):254-259.

40. Khalyfa A, Capdevila OS, Buazza MO, Serpero LD, KheirandishGozal L, Gozal D. Genome-wide gene expression profiling in children with non-obese obstructive sleep apnea. Sleep Med. 2009;10(1):75-86.

41. Kim J, Bhattacharjee R, Khalyfa A, et al. DNA methylation in inflammatory genes among children with obstructive sleep apnea. Am J Respir Crit Care Med. 2012;185(3):330-338.

42. Tan HL, Gozal D, Wang Y, et al. Alterations in circulating T-cell lymphocyte populations in children with obstructive sleep apnea. Sleep. 2013;36(6):913-922.

43. Kheirandish-Gozal L, Gozal D. Genotype-phenotype interactions in pediatric obstructive sleep apnea. Respir Physiol Neurobiol. Epub April 3, 2013.

44. Guilleminault C, Eldridge FL, Simmons FB, Dement WC. Sleep apnea in eight children. Pediatrics. 1976;58(1):23-30.

45. Serratto M, Harris VJ, Carr I. Upper airways obstruction. Presentation with systemic hypertension. Arch Dis Child. 1981;56(2):153-155.

46. Ross RD, Daniels SR, Loggie JM, Meyer RA, Ballard ET. Sleep apneaassociated hypertension and reversible left ventricular hypertrophy. J Pediatr. 1987;111(2):253-255.

47. Adegunsoye A, Ramachandran S. Etiopathogenetic mechanisms of pulmonary hypertension in sleep-related breathing disorders. Pulm Med. 2012;2012:273591.

48. Nisbet RE, Graves AS, Kleinhenz DJ, et al. The role of NADPH oxidase in chronic intermittent hypoxia-induced pulmonary hypertension in mice. Am J Respir Cell Mol Biol. 2009;40(5):601-609.

49. Abman SH, Ivy DD. Recent progress in understanding pediatric pulmonary hypertension. Curr Opin Pediatr. 2011;23(3):298-304.

50. Marcus CL, Greene MG, Carroll JL. Blood pressure in children with obstructive sleep apnea. Am J Respir Crit Care Med. 1998;157(4 Pt 1): 1098-1103.

51. Kohyama J, Ohinata JS, Hasegawa T. Blood pressure in sleep disordered breathing. Arch Dis Child. 2003;88(2):139-142.

52. Horne RS, Yang JS, Walter LM, et al. Elevated blood pressure during sleep and wake in children with sleep-disordered breathing. Pediatrics. 2011;128(1):e85-e92.

53. Amin RS, Carroll JL, Jeffries JL, et al. Twenty-four-hour ambulatory blood pressure in children with sleep-disordered breathing. Am J Respir Crit Care Med. 2004;169(8):950-956.

54. Verdecchia P, Schillaci G, Borgioni C, et al. Altered circadian blood pressure profile and prognosis. Blood Press Monit. 1997;2(6):347-352.

55. Amin R, Somers VK, McConnell K, et al. Activity-adjusted 24-hour ambulatory blood pressure and cardiac remodeling in children with sleep disordered breathing. Hypertension. 2008;51(1):84-91.

56. Nisbet LC, Yiallourou SR, Walter LM, Horne RS. Blood pressure regulation, autonomic control and sleep disordered breathing in children. Sleep Med Rev. Epub July 12, 2013.

57. Li AM, Au CT, Ho C, Fok TF, Wing YK. Blood pressure is elevated in children with primary snoring. J Pediatr. 2009;155(3):362-368. e1.

58. Kwok KL, Ng DK, Cheung YF. BP and arterial distensibility in children with primary snoring. Chest. 2003;123(5):1561-1566.

59. Goldbart AD, Levitas A, Greenberg-Dotan S, et al. B-type natriuretic peptide and cardiovascular function in young children with obstructive sleep apnea. Chest. 2010;138(3):528-535.

60. Gozal D, Kheirandish-Gozal L, Serpero LD, Sans Capdevila O, Dayyat E. Obstructive sleep apnea and endothelial function in schoolaged nonobese children: effect of adenotonsillectomy. Circulation. 2007;116(20):2307-2314

61. Kheirandish-Gozal L, Bhattacharjee R, Kim J, Clair HB, Gozal D. Endothelial progenitor cells and vascular dysfunction in children with obstructive sleep apnea. Am J Respir Crit Care Med. 2010;182(1): 92-97.

62. Kheirandish-Gozal L, Etzioni T, Bhattacharjee R, et al. Obstructive sleep apnea in children is associated with severity-dependent deterioration in overnight endothelial function. Sleep Med. 2013;14(6):526-531. 
63. Dubern B, Aggoun Y, Boulé M, Fauroux B, Bonnet D, Tounian P. Arterial alterations in severely obese children with obstructive sleep apnoea. Int $J$ Pediatr Obes. 2010;5(3):230-236.

64. Bhattacharjee R, Kim J, Alotaibi WH, Kheirandish-Gozal L, Capdevila OS, Gozal D. Endothelial dysfunction in children without hypertension: potential contributions of obesity and obstructive sleep apnea. Chest. 2012;141(3):682-691.

65. Gozal D, Kheirandish-Gozal L. The obesity epidemic and disordered sleep during childhood and adolescence. Adolesc Med State Art Rev. 2010;21(3):480-490, viii.

66. Pearson TA, Mensah GA, Alexander RW, et al; Centers for Disease Control and Prevention; American Heart Association. Markers of inflammation and cardiovascular disease: application to clinical and public health practice: A statement for healthcare professionals from the Centers for Disease Control and Prevention and the American Heart Association. Circulation. 2003;107(3):499-511.

67. Pasceri V, Willerson JT, Yeh ET. Direct proinflammatory effect of C-reactive protein on human endothelial cells. Circulation. 2000; 102(18):2165-2168.

68. Pasceri V, Cheng JS, Willerson JT, Yeh ET, Chang J. Modulation of C-reactive protein-mediated monocyte chemoattractant protein-1 induction in human endothelial cells by anti-atherosclerosis drugs. Circulation. 2001;103(21):2531-2534.

69. Kheirandish-Gozal L, Capdevila OS, Tauman R, Gozal D. Plasma C-reactive protein in nonobese children with obstructive sleep apnea before and after adenotonsillectomy. J Clin Sleep Med. 2006;2(3): 301-304.

70. Gozal D, Kheirandish-Gozal L, Bhattacharjee R, Kim J. C-reactive protein and obstructive sleep apnea syndrome in children. Front Biosci (Elite Ed). 2012;4:2410-2422.

71. Ingram DG, Matthews CK. Effect of adenotonsillectomy on c-reactive protein levels in children with obstructive sleep apnea: a meta-analysis. Sleep Med. 2013;14(2):172-176.

72. Gozal D, Kaditis AG, Khalyfa A, et al. Association between variants in CRP and IL-6 genes and susceptibility to OSA in children: A candidategene association study in European American and South-East European populations. In press 2013.

73. O'Brien LM, Serpero LD, Tauman R, Gozal D. Plasma adhesion molecules in children with sleep-disordered breathing. Chest. 2006;129(4):947-953.

74. Kim J, Bhattacharjee R, Snow AB, Capdevila OS, KheirandishGozal L, Gozal D. Myeloid-related protein 8/14 levels in children with obstructive sleep apnoea. Eur Respir J. 2010;35(4):843-850.

75. Kim J, Bhattacharjee R, Kheirandish-Gozal L, Spruyt K, Gozal D. Circulating microparticles in children with sleep disordered breathing. Chest. 2011;140(2):408-417.

76. Bhushan B, Khalyfa A, Spruyt K, et al. Fatty-acid binding protein 4 gene polymorphisms and plasma levels in children with obstructive sleep apnea. Sleep Med. 2011;12(7):666-671.

77. Punjabi NM, Sorkin JD, Katzel LI, Goldberg AP, Schwartz AR, Smith PL. Sleep-disordered breathing and insulin resistance in middleaged and overweight men. Am J Respir Crit Care Med. 2002;165(5): 677-682.

78. Lam JC, Mak JC, Ip MS. Obesity, obstructive sleep apnoea and metabolic syndrome. Respirology. 2012;17(2):223-236.

79. Assoumou HG, Gaspoz JM, Sforza E, et al. Obstructive sleep apnea and the metabolic syndrome in an elderly healthy population: the SYNAPSE cohort. Sleep Breath. 2012;16(3):895-902.

80. Basoglu OK, Sarac F, Sarac S, Uluer H, Yilmaz C. Metabolic syndrome, insulin resistance, fibrinogen, homocysteine, leptin, and C-reactive protein in obese patients with obstructive sleep apnea syndrome. Ann Thorac Med. 2011;6(3):120-125.

81. Pillai A, Warren G, Gunathilake W, Idris I. Effects of sleep apnea severity on glycemic control in patients with type 2 diabetes prior to continuous positive airway pressure treatment. Diabetes Technol Ther. 2011;13(9):945-949.
82. Bhushan B, Misra A, Guleria R. Obstructive sleep apnea is independently associated with the metabolic syndrome in obese Asian Indians in northern India. Metab Syndr Relat Disord. 2010;8(5): 431-435.

83. Ahmed QA. Metabolic complications of obstructive sleep apnea syndrome. Am J Med Sci. 2008;335(1):60-64.

84. Redline S, Storfer-Isser A, Rosen CL, et al. Association between metabolic syndrome and sleep-disordered breathing in adolescents. Am J Respir Crit Care Med. 2007;176(4):401-408.

85. Koren D, Levitt Katz LE, Brar PC, Gallagher PR, Berkowitz RI, Brooks LJ. Sleep architecture and glucose and insulin homeostasis in obese adolescents. Diabetes Care. 2011;34(11):2442-2447.

86. Lesser DJ, Bhatia R, Tran WH, et al. Sleep fragmentation and intermittent hypoxemia are associated with decreased insulin sensitivity in obese adolescent Latino males. Pediatr Res. 2012;72(3) 293-298.

87. Tauman R, O’Brien LM, Ivanenko A, Gozal D. Obesity rather than severity of sleep-disordered breathing as the major determinant of insulin resistance and altered lipidemia in snoring children. Pediatrics. 2005;116(1):e66-e73.

88. Kaditis AG, Alexopoulos EI, Damani E, et al. Obstructive sleepdisordered breathing and fasting insulin levels in nonobese children. Pediatr Pulmonol. 2005;40(6):515-523.

89. Gozal D, Capdevila OS, Kheirandish-Gozal L. Metabolic alterations and systemic inflammation in obstructive sleep apnea among nonobese and obese prepubertal children. Am J Respir Crit Care Med. 2008;177(10):1142-1149.

90. Khalyfa A, Gharib SA, Kim J, et al. Peripheral blood leukocyte gene expression patterns and metabolic parameters in habitually snoring and non-snoring children with normal polysomnographic findings. Sleep. 2011;34(2):153-160.

91. Zong J, Liu Y, Huang Y, et al. Serum lipids alterations in adenoid hypertrophy or adenotonsillar hypertrophy children with sleep disordered breathing. Int J Pediatr Otorhinolaryngol. 2013;77(5): 717-720.

92. Kheirandish-Gozal L, Sans Capdevila O, Kheirandish E, Gozal D. Elevated serum aminotransferase levels in children at risk for obstructive sleep apnea. Chest. 2008;133(1):92-99.

93. Verhulst SL, Jacobs S, Aerts L, et al. Sleep-disordered breathing: a new risk factor of suspected fatty liver disease in overweight children and adolescents? Sleep Breath. 2009;13(2):207-210.

94. Verhulst SL, Rooman R, Van Gaal L, De Backer W, Desager K. Is sleep-disordered breathing an additional risk factor for the metabolic syndrome in obese children and adolescents? Int $J$ Obes (Lond). 2009;33(1):8-13.

95. Gozal D. Sleep-disordered breathing and school performance in children. Pediatrics. 1998;102(3 Pt 1):616-620.

96. Chervin RD, Ruzicka DL, Hoban TF, et al. Esophageal pressures, polysomnography, and neurobehavioral outcomes of adenotonsillectomy in children. Chest. 2012;142(1):101-110.

97. Giordani B, Hodges EK, Guire KE, et al. Changes in neuropsychological and behavioral functioning in children with and without obstructive sleep apnea following Tonsillectomy. J Int Neuropsychol Soc. 2012;18(2):212-222.

98. Landau YE, Bar-Yishay O, Greenberg-Dotan S, Goldbart AD, Tarasiuk A, Tal A. Impaired behavioral and neurocognitive function in preschool children with obstructive sleep apnea. Pediatr Pulmonol. 2012;47(2):180-188.

99. Bourke R, Anderson V, Yang JS, et al. Cognitive and academic functions are impaired in children with all severities of sleep-disordered breathing. Sleep Med. 2011;12(5):489-496.

100. Garetz SL. Behavior, cognition, and quality of life after adenotonsillectomy for pediatric sleep-disordered breathing: summary of the literature. Otolaryngol Head Neck Surg. 2008;138(Suppl 1): S19-S26.

101. Wei JL, Bond J, Mayo MS, Smith HJ, Reese M, Weatherly RA. Improved behavior and sleep after adenotonsillectomy in children with sleep-disordered breathing: long-term follow-up. Arch Otolaryngol Head Neck Surg. 2009;135(7):642-646. 
102. Wei JL, Mayo MS, Smith HJ, Reese M, Weatherly RA. Improved behaviour and sleep after adenotonsillectomy in children with sleep-disordered breathing. Arch Otolaryngol Head Neck Surg. 2007;133(10):974-979.

103. Abman S, Jobe A, Chernick V, et al; NHLBI working group report. Strategic plan for pediatric respiratory diseases research: an NHLBI working group report. Pediatr Pulmonol. 2009;44(1):2-13.

104. Gozal D, Kheirandish-Gozal L. Neurocognitive and behavioral morbidity in children with sleep disorders. Curr Opin Pulm Med. 2007;13(6): 505-509.

105. Chervin RD, Ruzicka DL, Giordani BJ, et al. Sleep-disordered breathing, behaviour, and cognition in children before and after adenotonsillectomy. Pediatrics. 2006;117(4):e769-e778.

106. Montgomery-Downs HE, Crabtree VM, Gozal D. Cognition, sleep and respiration in at-risk children treated for obstructive sleep apnoea. Eur Respir J. 2005;25(2):336-342.

107. Friedman BC, Hendeles-Amitai A, Kozminsky E, et al. Adenotonsillectomy improves neurocognitive function in children with obstructive sleep apnea syndrome. Sleep. 2003;26(8):999-1005

108. Kaemingk KL, Pasvogel AE, Goodwin JL, et al. Learning in children and sleep disordered breathing: findings of the Tucson Children's Assessment of Sleep Apnea (tuCASA) prospective cohort study. J Int Neuropsychol Soc. 2003;9(7):1016-1026.

109. Kheirandish-Gozal L, De Jong MR, Spruyt K, Chamuleau SA, Gozal D. Obstructive sleep apnoea is associated with impaired pictorial memory task acquisition and retention in children. Eur Respir J. 2010;36(1):164-169

110. O'Brien LM, Mervis CB, Holbrook CR, et al. Neurobehavioral implications of habitual snoring in children. Pediatrics. 2004;114(1): 44-49.

111. Barnes ME, Gozal D, Molfese DL. Attention in children with obstructive sleep apnoea: an event-related potentials study. Sleep Med. 2012;13(4):368-377.

112. Barnes ME, Huss EA, Garrod KN, et al. Impairments in attention in occasionally snoring children: an event-related potential study. Dev Neuropsychol. 2009;34(5):629-649.

113. Perfect MM, Archbold K, Goodwin JL, Levine-Donnerstein D, Quan SF. Risk of behavioral and adaptive functioning difficulties in youth with previous and current sleep disordered breathing. Sleep. 2013;36(4):517B-525B.

114. Gozal D, Crabtree VM, Sans Capdevila O, Witcher LA, KheirandishGozal L. C-reactive protein, obstructive sleep apnea, and cognitive dysfunction in school-aged children. Am J Respir Crit Care Med. 2007;176(2):188-193.

115. Gozal D, Khalyfa A, Capdevila OS, Kheirandish-Gozal L, Khalyfa AA, Kim J. Cognitive function in prepubertal children with obstructive sleep apnea: a modifying role for NADPH oxidase p22 subunit gene polymorphisms? Antioxid Redox Signal. 2012;16(2):171-177.

116. Gozal D, Sans Capdevila O, McLaughlin Crabtree V, Serpero LD, Witcher LA, Kheirandish-Gozal L. Plasma IGF-1 levels and cognitive dysfunction in children with obstructive sleep apnea. Sleep Med. 2009;10(2):167-173.

117. Gozal D, Capdevila OS, Kheirandish-Gozal L, Crabtree VM. APOE epsilon 4 allele, cognitive dysfunction, and obstructive sleep apnea in children. Neurology. 2007;69(3):243-249.

118. Khadra MA, McConnell K, VanDyke R, et al. Determinants of regional cerebral oxygenation in children with sleep-disordered breathing. Am $J$ Respir Crit Care Med. 2008;178(8):870-875.

119. Hogan AM, Hill CM, Harrison D, Kirkham FJ. Cerebral blood flow velocity and cognition in children before and after adenotonsillectomy. Pediatrics. 2008;122(1):75-82.

120. Gozal D, Kheirandish-Gozal L, Bhattacharjee R, Spruyt K. Neurocognitive and endothelial dysfunction in children with obstructive sleep apnea. Pediatrics. 2010;126(5):e1161-e1167.

121. Gozal D, Pope DW. Snoring during early childhood and academic performance at ages thirteen to fourteen years. Pediatrics. 2001;107(6): 1394-1399.
122. Melendres MC, Lutz JM, Rubin ED, Marcus CL. Daytime sleepiness and hyperactivity in children with suspected sleep-disordered breathing. Pediatrics. 2004;114(3):768-775.

123. Khalyfa A, Serpero LD, Kheirandish-Gozal L, Capdevila OS, Gozal D. TNF- $\alpha$ gene polymorphisms and excessive daytime sleepiness in pediatric obstructive sleep apnea. J Pediatr. 2011;158(1): 77-82.

124. Tarasiuk A, Greenberg-Dotan S, Simon-Tuval T, et al. Elevated morbidity and health care use in children with obstructive sleep apnea syndrome. Am J Respir Crit Care Med. 2007;175(1):55-61.

125. Reuveni H, Simon T, Tal A, Elhayany A, Tarasiuk A. Health care services utilization in children with obstructive sleep apnea syndrome. Pediatrics. 2002;110(1 Pt 1):68-72.

126. Tarasiuk A, Simon T, Tal A, Reuveni H. Adenotonsillectomy in children with obstructive sleep apnea syndrome reduces health care utilization. Pediatrics. 2004;113(2):351-356.

127. Tsou YA, Lin CC, Lai CH, et al. Does Adenotonsillectomy really reduced clinic visits for pediatric upper respiratory tract infections? A national database study in Taiwan. Int J Pediatr Otorhinolaryngol. 2013;77(5):677-681.

128. Weider DJ, Hauri PJ. Nocturnal enuresis in children with upper airway obstruction. Int J Pediatr Otorhinolaryngol. 1985;9(2):173-182.

129. Jeyakumar A, Rahman SI, Armbrecht ES, Mitchell R. The association between sleep-disordered breathing and enuresis in children. Laryngoscope. 2012;122(8):1873-1877.

130. Alexopoulos EI, Kostadima E, Pagonari I, Zintzaras E, Gourgoulianis K, Kaditis AG. Association between primary nocturnal enuresis and habitual snoring in children. Urology. 2006;68(2):406-409.

131. Lehmann GC, Bell TR, Kirkham FJ, et al. Enuresis associated with sleep disordered breathing in children with sickle cell anemia. J Urol. 2012;188(Suppl 4):S1572-S1576.

132. Sans Capdevila O, Crabtree VM, Kheirandish-Gozal L, Gozal D. Increased morning brain natriuretic peptide levels in children with nocturnal enuresis and sleep-disordered breathing: a community-based study. Pediatrics. 2008;121(5):e1208-e1214.

133. Rechtschaffen A, Kales A, editors. A manual of standardized terminology, techniques and scoring system for sleep stages of human subjects. Los Angeles: Brain Information Service/Brain Research Institute, University of California; 1968.

134. Berry RB, Brooks R, Gamaldo CE, Harding SM, Marcus CL, Vaughn BV; the American Academy of Sleep Medicine. The AASM Manual for the Scoring of Sleep and Associated Events: Rules, Terminology and Technical Specifications. 2nd ed. Darien, IL: American Academy of Sleep Medicine; 2012.

135. Kaditis A, Kheirandish-Gozal L, Gozal D. Algorithm for the diagnosis and treatment of pediatric OSA: a proposal of two pediatric sleep centers. Sleep Med. 2012;13(3):217-227.

136. Gozal D, Kheirandish-Gozal L. New approaches to the diagnosis of sleep-disordered breathing in children. Sleep Med. 2010;11(7): $708-713$.

137. Marcus CL, Brooks LJ, Draper KA, et al; American Academy of Pediatrics. Diagnosis and management of childhood obstructive sleep apnea syndrome. Pediatrics. 2012;130(3):576-584.

138. Guilleminault C, Huang YS, Glamann C, Li K, Chan A. Adenotonsillectomy and obstructive sleep apnea in children: a prospective survey. Otolaryngol Head Neck Surg. 2007;136(2):169-175.

139. Cantarella G, Viglione S, Forti S, Minetti A, Pignataro L. Comparing postoperative quality of life in children after microdebrider intracapsular tonsillotomy and tonsillectomy. Auris Nasus Larynx. 2012;39(4): 407-410.

140. Ericsson E, Lundeborg I, Hultcrantz E. Child behaviour and quality of life before and after tonsillotomy versus tonsillectomy. Int J Pediatr Otorhinolaryngol. 2009;73(9):1254-1262.

141. Marcus CL, Ward SL, Mallory GB, et al. Use of nasal continuous positive airway pressure as treatment of childhood obstructive sleep apnea. J Pediatr. 1995;127(1):88-94. 
142. Marcus CL, Rosen G, Ward SL, et al. Adherence to and effectiveness of positive airway pressure therapy in children with obstructive sleep apnea. Pediatrics. 2006;117(3):e442-e451.

143. Sawyer AM, Gooneratne NS, Marcus CL, Ofer D, Richards KC, Weaver TE. A systematic review of CPAP adherence across age groups: clinical and empiric insights for developing CPAP adherence interventions. Sleep Med Rev. 2011;15(6):343-356.

144. DiFeo N, Meltzer LJ, Beck SE, et al. Predictors of positive airway pressure therapy adherence in children: a prospective study. $J$ Clin Sleep Med. 2012;8(3):279-286.

145. McGinley B, Halbower A, SchwartzAR, Smith PL, Patil SP, Schneider H. Effect of a high-flow open nasal cannula system on obstructive sleep apnea in children. Pediatrics. 2009;124(1):179-188.

146. Kheirandish-Gozal L, Kim J, Goldbart AD, Gozal D. Novel pharmacological approaches for treatment of obstructive sleep apnea in children. Expert Opin Investig Drugs. 2013;22(1):71-85.

147. Goldbart AD, Goldman JL, Li RC, Brittian KR, Tauman R, Gozal D. Differential expression of cysteinyl leukotriene receptors 1 and 2 in tonsils of children with obstructive sleep apnea syndrome or recurrent infection. Chest. 2004;126(1):13-18.

148. Dayyat E, Serpero LD, Kheirandish-Gozal L, et al. Leukotriene pathways and in vitro adenotonsillar cell proliferation in children with obstructive sleep apnea. Chest. 2009;135(5):1142-1149.

149. Goldbart AD, Goldman JL, Veling MC, Gozal D. Leukotriene modifier therapy for mild sleep-disordered breathing in children. Am J Respir Crit Care Med. 2005;172(3):364-370.

150. Goldbart AD, Greenberg-Dotan S, Tal A. Montelukast for children with obstructive sleep apnea: a double-blind, placebo-controlled study. Pediatrics. 2012;130(3):e575-e580.

151. Kheirandish-Gozal L, Serpero LD, Dayyat E, et al. Corticosteroids suppress in vitro tonsillar proliferation in children with obstructive sleep apnoea. Eur Respir J. 2009;33(5):1077-1084.

152. Kheirandish-Gozal L, Gozal D. Intranasal budesonide treatment for children with mild obstructive sleep apnea syndrome. Pediatrics 2008;122(1):e149-e155.

153. Brouillette RT, Manoukian JJ, Ducharme FM, et al. Efficacy of fluticasone nasal spray for pediatric obstructive sleep apnea. J Pediatr. 2001;138(6):838-844.

154. Kheirandish L, Goldbart AD, Gozal D. Intranasal steroids and oral leukotriene modifier therapy in residual sleep-disordered breathing after tonsillectomy and adenoidectomy in children. Pediatrics. 2006;117(1):e61-e66.

155. Pirelli P, Saponara M, Guilleminault C. Rapid maxillary expansion in children with obstructive sleep apnea syndrome. Sleep. 2004;27(4): 761-766.

156. Villa MP, Malagola C, Pagani J, et al. Rapid maxillary expansion in children with obstructive sleep apnea syndrome: 12-month follow-up. Sleep Med. 2007;8(2):128-134.

157. Villa MP, Miano S, Rizzoli A. Mandibular advancement devices are an alternative and valid treatment for pediatric obstructive sleep apnea syndrome. Sleep Breath. 2012;16(4):971-976.

158. Hartzell LD, Guillory RM, Munson PD, Dunham AK, Bower CM, Richter GT. Tongue base suspension in children with cerebral palsy and obstructive sleep apnea. Int J Pediatr Otorhinolaryngol. 2013;77(4):534-537.
159. Guilleminault C, Huang YS, Monteyrol PJ, Sato R, Quo S, Lin CH. Critical role of myofascial reeducation in pediatric sleep-disordered breathing. Sleep Med. 2013;14(6):518-525.

160. Huang YS, Guilleminault C. Pediatric obstructive sleep apnea and the critical role of oral-facial growth: evidences. Front Neurol. 2012;3:184.

161. Ruoff CM, Guilleminault C. Orthodontics and sleep-disordered breathing. Sleep Breath. 2012;16(2):271-273.

162. Guilleminault C, Monteyrol PJ, Huynh NT, Pirelli P, Quo S, Li K. Adeno-tonsillectomy and rapid maxillary distraction in pre-pubertal children, a pilot study. Sleep Breath. 2011;15(2):173-177.

163. Lin AC, Koltai PJ. Sleep endoscopy in the evaluation of pediatric obstructive sleep apnea. Int J Pediatr. 2012;2012:576719.

164. Truong MT, Woo VG, Koltai PJ. Sleep endoscopy as a diagnostic tool in pediatric obstructive sleep apnea. Int J Pediatr Otorhinolaryngol. 2012;76(5):722-727.

165. Maturo SC, Hartnick CJ. Pediatric lingual tonsillectomy. $A d v$ Otorhinolaryngol. 2012;73:109-111.

166. Sedaghat AR, Flax-Goldenberg RB, Gayler BW, Capone GT, Ishman SL. A case-control comparison of lingual tonsillar size in children with and without Down syndrome. Laryngoscope. 2012;122(5):1165-1169.

167. Abdel-Aziz M, Ibrahim N,AhmedA, El-Hamamsy M,Abdel-Khalik MI, El-Hoshy H. Lingual tonsils hypertrophy; a cause of obstructive sleep apnea in children after adenotonsillectomy: operative problems and management. Int J Pediatr Otorhinolaryngol. 2011;75(9): 1127-1131.

168. Fricke BL, Donnelly LF, Shott SR, et al. Comparison of lingual tonsil size as depicted on MR imaging between children with obstructive sleep apnea despite previous tonsillectomy and adenoidectomy and normal controls. Pediatr Radiol. 2006;36(6):518-523.

169. Guimaraes CV, Kalra M, Donnelly LF, et al. The frequency of lingual tonsil enlargement in obese children. AJR Am J Roentgenol. 2008;190(4):973-975.

170. Schaaf WE, Wootten CT, Donnelly LF, Ying J, Shott SR. Findings on MR sleep studies as biomarkers to predict outcome of genioglossus advancement in the treatment of obstructive sleep apnea in children and young adults. AJR Am J Roentgenol. 2010;194(5):1204-1209.

171. Donnelly LF, Shott SR, LaRose CR, Chini BA, Amin RS. Causes of persistent obstructive sleep apnea despite previous tonsillectomy and adenoidectomy in children with down syndrome as depicted on static and dynamic cine MRI. AJR Am J Roentgenol. 2004;183(1): 175-181.

172. Gozal D. Serum, urine, and breath-related biomarkers in the diagnosis of obstructive sleep apnea in children: is it for real? Curr Opin Pulm Med. 2012;18(6):561-567.

173. Kheirandish-Gozal L, Gozal D. The multiple challenges of obstructive sleep apnea in children: diagnosis. Curr Opin Pediatr. 2008;20(6): 650-653.

174. Kheirandish-Gozal L, McManus CJ, Kellermann GH, Samiei A, Gozal D. Urinary neurotransmitters are selectively altered in children with obstructive sleep apnea and predict cognitive morbidity. Chest. 2013;143(6):1576-1583.
Nature and Science of Sleep

\section{Publish your work in this journal}

Nature and Science of Sleep is an international, peer-reviewed, open access journal covering all aspects of sleep science and sleep medicine, including the neurophysiology and functions of sleep, the genetics of sleep, sleep and society, biological rhythms, dreaming, sleep disorders and therapy, and strategies to optimize healthy sleep. The journal welcomes

\section{Dovepress}

original research, clinical \& epidemiological studies, reviews \& evaluations, case reports and extended reports. The manuscript management system is completely online and includes a very quick and fair peerreview system, which is all easy to use. Visit http://www.dovepress.com/ testimonials.php to read real quotes from published authors. 